\title{
ANALYZING TRENDS IN REFERENCE EVAPOTRANSPIRATION IN NORTHWEST PART OF IRAN
}

\author{
Mohammadreza Azizzadeh ${ }^{1}$, Khadije Javan ${ }^{1}$ \\ 1 Department of Geography, Payam Noor University, PO Box 3697-19395, Tehran, Iran, e-mail: m_azizzadeh@ \\ pnu.ac.ir; kjavan20@yahoo.com
}

Received: 2015.01 .06

Accepted: 2015.02.04

Published: 2015.04.01

\begin{abstract}
Evapotranspiration is one of the most important components of the hydrological cycle. It is essential in all of hydro climatological studies, irrigation and drainage calculations, water balance, and crop water requirements. The aim of this study is to investigate temporal trends of reference evapotranspiration (ETo) in the Northwest part of Iran. For this purpose, the meteorological data from 20 synoptic stations over a 22-year time period (1986-2007) were used. After the calculation of ETo using the Penman-Monteith FAO-56 method, the non-parametric Mann-Kendall test was used to investigate the temporal trends on monthly, seasonal and annual scales. The Sen's estimator method was used and to calculate the slope of the trend line. The results indicated that the ETo trend was increasing (positive) in various months, except for the Sarab station in December. On a monthly scale, the Maragheh station showed the highest positive slope in August, and the Bijar station showed the highest negative slope in May. $43.34 \%$ of the stations showed a significant trend, and 56.66\% did not show a significant trend. In seasonal and annual time periods there was not a significant decreasing trend in any of the stations. The analysis of the results shows that in the spring $20 \%$, in the summer $55 \%$, in the fall $70 \%$, in the winter $75 \%$, and on an annual scale $60 \%$ of the stations under study showed an increasing trend. For modeling these changes, the spatial distribution of ETo trends (on monthly, seasonal, and annual scales) were mapped in ArcGIS. Final models determine that most stations in this study show an increasing trend on monthly, seasonal and annual scales.
\end{abstract}

Keywords: reference evapotranspiration, trend, Mann-Kendall test, Sen's estimator, Northwest of Iran.

\section{INTRODUCTION}

Evapotranspiration, following precipitation, is the most important component of the hydrological cycle. It is one of the main components of water balance, and proper irrigation scheduling programs in any location. Limited water resources and undesirable and uneconomic use of it are the main factors that limit agricultural development and food production in Iran. Therefore, it is essential to have sufficient information about the changes in evapotranspiration for accurate planning of agricultural irrigation and water resource management in any region.

In recent years, the issue of climate change and its impacts has created many challenges in international communities. Such that all nations attempt to determine the change in the components of climate and its process and direction. In addition to elements such as temperature and precipitation, which are often studied, recently other elements such as evapotranspiration have been of interest to researchers.

One of popular methods for analyzing hydrometeorological time series is the study of the presence or absence of trends in them using statistical tests [Hajjam, 2008, p. 157]. Overall, two statistical methods - parametric and non-parametric- exist for the analysis of trends in time series. However, non-parametric statistical method is used more widely in hydro-meteorological studies. Parametric methods are often based on a re- 
gression relationship between a series of data. However, for series of data that do not fit any specific statistical distribution or have a high measure of skewness or kurtosis, the use of nonparametric methods is more suitable. Among the non-parametric tests, the Mann-Kendall test is the best method for the study of uniform data [Xu et al., 2003, p. 145]. This method is very suitable for time series without normal distribution and it is not sensitive to outlier values that are visible in most time series [Kumar et al., 2009, p. 172].

Several studies in relation to changes in evapotranspiration in different parts of the world have been performed. Some of them are as follows.

Thomas [1999] studied the trend in the potential evapotranspiration changes in China using a parametric method. His research showed a decreasing trend for the entire country and an increasing trend for northwest and southeast China. He reported the number of hours of sunshine as the main factor for the changes in potential evapotranspiration in China.

Bandyopadhyay et al. [2007] studied the trend in evapotranspiration in the reference crop in India using the Mann-Kendall test, with statistics from 133 stations during the statistical time period from 1971 to 2002. They determined a decreasing trend in the region. They stated that this decrease was due to a significant increase in relative humidity and also a decrease in wind speed.

Song et al. [2010] studied the time and regional distribution of ETo in the Northern valley in China during the statistical time period from 1961 to 2006. They determined the maximum yearly ETo occurred in central and western China, whereas the minimum occurred in eastern China.

Tabari et al. [2011] studied the trend in evapotranspiration in 20 synoptic stations in western Iran during the period from 1966 to 2005 using the Mann-Kendall method, and used the Sen's estimator method to determine the slope of the trend line. They concluded that the referential evapotranspiration had increasing and decreasing trends, where in 70 percent of the stations showed an increasing trend on an annual scale, and that the increasing trends occurred in the summer and winter.

Zhang et al. [2011] studied the changes in evapotranspiration potential in China using the Penman-Monteith method and the Mann-Kendall test. They used data from 590 meteorological stations, and concluded that seasonal and annual potential evapotranspiration in the east, south and northwestern China showed a decreasing change. The different meteorological variables are factors cause change in evapotranspiration potential, such that in eastern China net radiation changes, and in northwest China relative humidity are effective.

Dinpashoh et al. [2011] studied the trend in the evapotranspiration potential in Iran during the statistical period from 1965 to 2005, and concluded that the number of stations showing an increasing trend is more in Iran. Also, on a monthly time scale, they observed that increasing trends were more than decreasing ones.

Shirgholami et al. [2005] studied the trend in the potential evapotranspiration using data from 34 synoptic stations in Iran. They calculated the amount of potential evapotranspiration using the FAO-Penman-Monteith method, and used the Least-Squares method and the parametric ttest for testing the trend. They concluded that 12 percent of the stations showed a significant positive trend, $26 \%$ significant negative, and the rest showed no trend.

Sabzi-parvar et al. [2012] determined the trend of the reference evapotranspiration (ETo) in 13 synoptic stations in the country with warm climate in the period from 1957 to 2006 using the MannKendall and the Age-Estimating method. This study showed that 53 percent of the stations in different seasons or on an annual scale had a significant trend, and 47 percent were insignificant.

Sabzi-Parvar and Shadmani [2012] determined the time variation of the parameter reference evapotranspiration in arid regions of Iran using the nonparametric Mann-Kendall and Spearman tests, and in order to reduce the impact of correlation on the results, they used the TFPW method. The results showed an increasing trend for some cities, and a decreasing trend for others. A comparison of the functionality and power of the two tests on a significant statistical level showed that in most cases a noticeable correspondence in revealing trends in reference evapotranspiration exists between the two tests.

Ismailpour and Dinpashoh [2013] determined the trend in evapotranspiration potential in 6 stations located in the south of the Aras river basin in the period from 1986 to 2008 using the MannKendall test. The results showed that the trend is variable at different times. Among the stations studied, Khoy has experienced a significant increase on an annual scale. 
Considering the studies performed relating to the subject of this research it was noted that so far an integral study on the trend in the changes in the evapotranspiration in the northwest of Iran has not been performed. Therefore, the main objectives of this study are:

- Estimating the reference evapotranspiration using the Penman-Monteith-FAO-56 in the Northwest.

- Studying the trend of its variations using the nonparametric Mann-Kendall method.

- Determining the slope of the significant trends using the Age-estimating method.

\section{ARTICLES AND METHODS}

\section{Data}

For studying the trend in the long term variations in the reference evapotranspiration (ETo) in northwestern Iran, monthly statistics from 20 select synoptic stations in the period from 1987 to 2007 were used. The parameters considered are:

- minimum temperature,

- maximum temperature,

- average temperature,

- minimum relative humidity,

- vapor pressure,

- wind speed,

- number of hours of sunlight.

To ensure the homogeneity of the data, Run test was used, and to fill the gaps in the data, the Averaging method was used. The specifications and the locations of the selected stations are given in Figure 1, and in Table 1.
Table 1. Specifications of the selected stations

\begin{tabular}{|l|r|r|c|}
\hline Station name & Longitude ${ }^{\circ} \mathrm{E}$ & Latitude $^{\circ} \mathrm{N}$ & Elevation \\
\hline Ahar & 4704 & 3826 & 1390.5 \\
\hline Ardebil & 4819 & 3813 & 1335.5 \\
\hline Bijar & 4737 & 3553 & 1883.5 \\
\hline Jolfa & 4540 & 3845 & 736.2 \\
\hline Khalkhal & 4832 & 3736 & 1797.4 \\
\hline Khoramdare & 4911 & 3611 & 1575 \\
\hline Khoy & 4459 & 3833 & 1198.7 \\
\hline Mahabad & 4542 & 3645 & 1352 \\
\hline Makoo & 4423 & 3922 & 1411.3 \\
\hline Maragheh & 4610 & 3721 & 1344 \\
\hline Mianeh & 4742 & 3727 & 1110 \\
\hline Oroomieh & 4503 & 3739 & 1328 \\
\hline Parsabad & 4755 & 3939 & 31.9 \\
\hline Piranshahr & 4508 & 3641 & 1443.5 \\
\hline Saghez & 4616 & 3515 & 1522.8 \\
\hline Sanandaj & 4700 & 3520 & 1373.4 \\
\hline Sarab & 4617 & 3756 & 1682 \\
\hline Tabriz & 4617 & 3605 & 1361 \\
\hline Takab & 4706 & 3623 & 1817.2 \\
\hline Zanjan & 4829 & 3641 & 1663 \\
\hline
\end{tabular}

\section{Research method}

- The Penman-Monteith-FAO-56 (PMF-56) Method.

This method, which has been introduced by Allen et al. [1998], was used to determine the reference evapotranspiration (ETo) in northwestern Iran. FAO has selected this method as the best for determining evapotranspiration. This method uses the following equation:

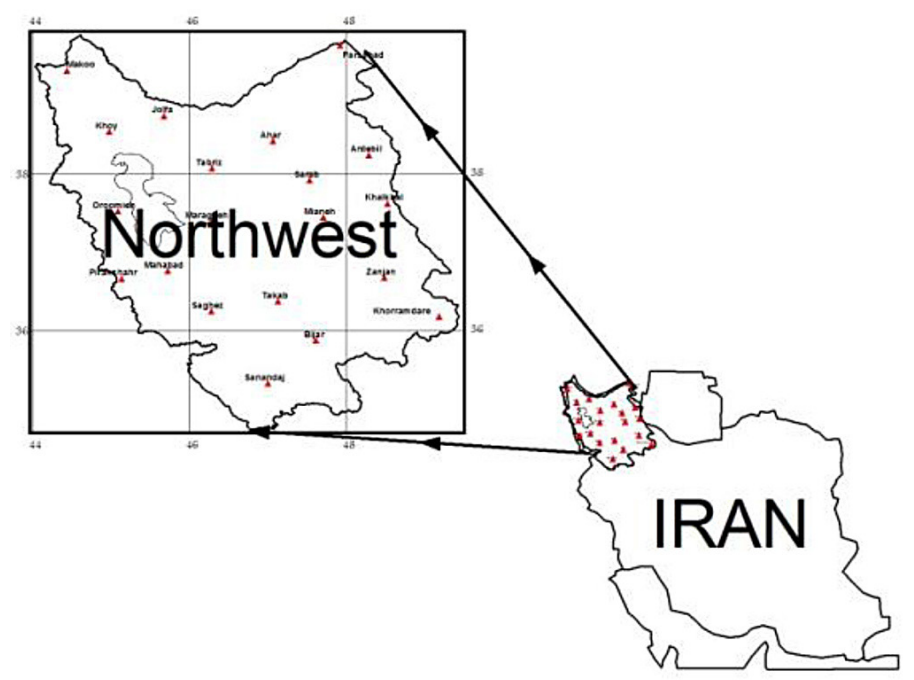

Figure 1. Geographic location of the region under study 


$$
\mathrm{ET}_{\mathrm{o}}=\frac{0.408 \Delta\left(\mathrm{R}_{\mathrm{n}}-\mathrm{G}\right)+\gamma\left\{\frac{900}{\mathrm{~T}+273}\right\} \mathrm{U}_{2}\left(\mathrm{e}_{\mathrm{a}}-\mathrm{e}_{\mathrm{d}}\right)}{\Delta+\gamma\left(1+0.34 \mathrm{U}_{2}\right)}
$$

In the above equation, the variables and parameters are defined as follows:

\begin{tabular}{|c|l|c|}
\hline Variable & \multicolumn{1}{|c|}{ Description } & Unit \\
\hline $\mathbf{E T o}$ & Reference evapotranspiration & $\mathrm{mm} / \mathrm{day}$ \\
\hline $\mathbf{R}_{\mathrm{n}}$ & $\begin{array}{l}\text { Net radiation on the surface of the } \\
\text { plants }\end{array}$ & $\mathrm{MJ} / \mathrm{m}^{2}$ \\
\hline $\mathbf{T}$ & Average temperature & ${ }^{\circ} \mathrm{C}$ \\
\hline $\mathbf{U}_{\mathbf{2}}$ & $\begin{array}{l}\text { Wind speed at 2m above the } \\
\text { surface }\end{array}$ & $\mathrm{m} / \mathrm{s}$ \\
\hline $\mathbf{e}_{\mathrm{a}} \mathbf{e}_{\mathbf{d}}$ & $\begin{array}{l}\text { Vapor pressure shortage at a height } \\
\text { of 2m }\end{array}$ & $\mathrm{KP}$ \\
\hline $\mathbf{\Delta}$ & Slant of the vapor pressure & $\mathrm{KP} /{ }^{\circ} \mathrm{C}$ \\
\hline V & Humidity factor & $\mathrm{KP} /{ }^{\circ} \mathrm{C}$ \\
\hline $\mathbf{G}$ & Heat transfer to the ground & $\begin{array}{c}\mathrm{MJ} / \mathrm{m}^{2} \text { per } \\
\text { day }\end{array}$ \\
\hline
\end{tabular}

The values of ETo were calculated monthly using REF-ET software [Allen, 2000].

- The Mann-Kendall Test.

This test was originally introduced by Mann (1945), and was then expanded by Kendall [1975] [Serrano et al. 1999]. This test is used to determine trends and their significance. This test also gives information about the starting point of the trend and sudden changes in the climate [Karaca et al. 1995]. One of the strong points of this test is its suitability for time series that do not fit into any specific statistical distribution. Another advantage of this test is that it is marginally influenced by outlier data which is seen in many time series. The Null Hypothesis of this test is that the data series does not follow a trend and is accidental, and the acceptance of the Alternative Hypothesis means that a trend does exist in the data series. The steps involved in performing this test are as follows:

Calculating the difference between the individual observances, performing the $s g n$ function, and determining the parameter $S$ :

$$
S=\sum_{k-1}^{n-1} \sum_{j=k+1}^{n} \operatorname{sgn}\left(x_{j}-x_{k}\right)
$$

In the above equation, $n$ is the number of observances, $x_{j}$ and $x_{k}$ are the $\mathrm{j}^{\text {th }}$ and the $\mathrm{k}^{\text {th }}$ elements respectively.

The sgn function is determined as follows:

$$
\operatorname{sgn}(x)=\left\{\begin{array}{lll}
+1 & \text { if } & \left(x_{j}-x_{k}\right)>0 \\
0 & \text { if } & \left(x_{j}-x_{k}\right)=0 \\
-1 & \text { if } & \left(x_{j}-x_{k}\right)<0
\end{array}\right.
$$

If $n>10$, variance (var) is determined as follows:

$$
\operatorname{Var}(s)=\frac{n(n-1)(2 n+5)-\sum_{i=1}^{m} t(t-1)(2 t+5)}{18}
$$

In the above equation, $n$ is the number of observances, $m$ is the number of series with at least one repeated element. Parameter $t$ indicates the abundance of elements with equal value.

Then, the statistic $Z$ is determined as follows:

$$
Z_{M K}=\left\{\begin{array}{llc}
\frac{s-1}{\sqrt{\operatorname{Var}(S)}} & \text { if } & S=0 \\
0 & \text { if } \quad S=0 \\
\frac{s+1}{\sqrt{\operatorname{Var}(S)}} & \text { if } & S=0
\end{array}\right.
$$

In a two-sided test, the Null Hypothesis is accepted if the following inequality is satisfied:

$$
|Z| \leq \mathrm{Z}_{\alpha / 2}
$$

where, the parameter $\alpha$ determines the level of significance considered by the test, and $Z_{\alpha}$ is the standard normal distribution statistic in the $\alpha$ significance level. Due to the fact that this test is two-sided, $\alpha / 2$ is used. In this test, a significance level of $95 \%$, and $99 \%$ is considered. A positive value of the statistic $Z$ indicates an increasing trend, whereas a negative $\mathrm{Z}$ indicates a decreasing trend [Hajjam et al. 2009, p. 160; Juraj et al. 2009, p. 475].

- The Sen's Estimator method.

Due to the non-parametric nature of the Mann-Kendall test, the Sen's estimating method was used to determine the slope of the trends. In this method, outlier data have a very small effect on the slope; this is its main advantage compared to the Linear Regression method [Novotny and Stefan, 2007, p. 336].

The slope between any pair of observances is calculated as follows:

$$
Q=\frac{X_{t}-X_{s}}{t-s}
$$

where $X_{t}$ and $X_{s}$ are the data at times $t$ and $s$ respectively, and $t$ occurs one time unit after $s$. Applying this equation to all pairs of data, a series of slopes are calculated. The slope of the trend $\left(Q_{\text {med }}\right)$ is then determined by finding the median of this series. A positive $Q_{\text {med }}$ indicates an increasing trend, and a negative one indicates a decreasing trend [Hajjam et al. 2009, p. 160; Juraj et al. 2009, p. 475].

\section{RESULTS AND DISCUSSION}

\section{Monthly time series}

After calculating the amounts for the reference evapotranspiration, the Statistic of the 
Mann-Kendall and the Sen's estimator methods for monthly time series were calculated, and the significance of the Statistic $\mathbf{Z}$ on a level of significance in of $95 \%$ and $99 \%$ was studied. The results of the Mann-Kendall test are shown in Table 2. As noted in this table, the reference evapotranspiration shows an increasing trend in various months, and it is only in the Sarab station in the month of December that the significant trend shows a decrease. In January, only the Takab station shows a significant increasing trend on a $99 \%$ level, and in the other stations being studied, a significant trend is not observed. In February, about half the stations show a significant trend.

In March, all stations, except the Sarab and the Saghez stations, show a significant increasing trend. In this month, on average, $90 \%$ of the region's stations show a significant trend. In April this number decreases and only eight stations in the region show a significant trend; in May this decline continues and it is only in the Tabriz and the Ardabil stations that a significant increasing trend is observed. From the month of June onward, the number of stations showing a trend increases, such that in August this number is 15, and in October it is 17. Again, in November and December the number of stations showing a sig- nificant trend, decreases. The highest amount of monthly increasing trend was seen in October in the Khoy station with a $\mathbf{Z}$ of 4.23, and the highest amount of monthly decreasing trend was seen in the Sarab station in December with a $\mathbf{Z}$ of -2.63 .

After determining the amounts and the direction of the trends, the slope of the trends over the months of the year were calculated using the Sen's estimator method, as shown in Table 3. From the results, shown in Table 3, we can note that in the Bijar, Maragheh, Saghez, Tabriz, and Ahar stations have had a considerable slope compared to the other stations.

The highest amount of the increasing monthly reference evapotranspiration trend with a slope of $0.106 \mathrm{~mm} /$ day, occurred in the Maragheh station in August, and its highest decreasing trend occurred in the Bijar station in May with a slope of $-0.045 \mathrm{~mm} /$ day (Figure 2).

In order to specify the scattering of the regions that have a significant trend, using the results of the Mann-Kendall test, the region was mapped out. The mapping of the region was carried out using the Kriging method. Figure 3 shows the regional distribution of the stations having a significant trend separated according to the monthly series.

Table 2. Mann-Kendall Statistic (Z) for reference evapotranspiration on a monthly scale

\begin{tabular}{|c|c|c|c|c|c|c|c|c|c|c|c|c|}
\hline Station name & Jan & Feb & Mar & Apr & May & Jun & July & Aug & Sep & Oct & Nov & Des \\
\hline Ahar & 1.17 & $2.32^{*}$ & $2.00^{*}$ & 0.82 & 0.40 & 1.40 & $3.10^{* *}$ & $3.41^{* *}$ & 1.36 & $3.23^{* *}$ & 0.77 & 1.38 \\
\hline Ardebil & 1.82 & $2.84^{* *}$ & $2.09^{*}$ & $2.09^{*}$ & $2.66^{* *}$ & 0.99 & 0.96 & $2.06^{*}$ & $2.55^{* *}$ & $2.48^{*}$ & 1.70 & 1.02 \\
\hline Bijar & 1.09 & 1.27 & $3.23^{* *}$ & $2.05^{*}$ & -1.30 & 0.15 & -0.18 & -0.54 & -0.18 & 1.30 & -0.45 & -0.21 \\
\hline Jolfa & 0.26 & 1.17 & $2.49^{*}$ & 1.11 & 0.03 & 1.30 & 1.02 & $2.62^{* *}$ & 0.93 & $2.11^{*}$ & $2.84^{* *}$ & 0.58 \\
\hline Khalkhal & 1.71 & $2.82^{* *}$ & $2.96^{* *}$ & $2.59^{* *}$ & 0.39 & 0.76 & 1.42 & $2.99^{* *}$ & $2.15^{*}$ & $2.71^{* *}$ & 0.39 & 0.12 \\
\hline Khoramdare & 1.51 & $2.99^{* *}$ & $3.41^{* *}$ & $2.17^{*}$ & 1.36 & $3.00^{* *}$ & 1.33 & $2.03^{*}$ & 1.36 & $2.62^{* *}$ & 0.62 & 1.00 \\
\hline Khoy & -0.79 & 1.40 & $2.55^{* *}$ & 1.58 & 0.62 & $3.68^{* *}$ & $3.75^{* *}$ & $4.23^{* *}$ & $3.62^{* *}$ & $4.66^{* *}$ & $2.35 \mathrm{v}$ & 0.27 \\
\hline Mahabad & 1.27 & $2.33^{*}$ & $3.30^{* *}$ & $2.68^{* *}$ & 0.54 & $2.51^{*}$ & $2.66^{* *}$ & $3.44^{* *}$ & $2.70^{* *}$ & $2.76^{* *}$ & 1.11 & 1.10 \\
\hline Makoo & -0.51 & 1.82 & $2.54^{*}$ & 1.16 & 1.07 & 1.80 & 1.34 & $2.91^{* *}$ & 1.75 & $4.03^{* *}$ & $2.90^{* *}$ & 1.38 \\
\hline Maragheh & 0.79 & $2.04^{*}$ & $2.85^{* *}$ & $2.21^{*}$ & 1.68 & $3.33^{* *}$ & $1.97^{*}$ & $3.64^{* *}$ & $2.88^{* *}$ & $4.29^{* *}$ & $3.12^{* *}$ & $2.37^{*}$ \\
\hline Mianeh & -0.13 & 1.60 & $2.08^{*}$ & 0.39 & 0.09 & 1.30 & -0.15 & $2.08^{*}$ & $2.72^{* *}$ & $1.72^{*}$ & 0.88 & -0.80 \\
\hline Oroomieh & -0.79 & 1.00 & $2.31^{*}$ & 1.85 & 0.68 & $2.62^{* *}$ & $2.79^{* *}$ & $3.28^{* * *}$ & $2.67^{* *}$ & $2.31^{*}$ & 0.00 & -1.24 \\
\hline Parsabad & 1.87 & $3.40 v$ & $2.67^{* *}$ & 1.30 & 1.35 & -0.06 & 0.51 & -0.42 & -0.11 & $3.53^{* *}$ & $3.62^{* *}$ & $1.99^{*}$ \\
\hline Piranshahr & 0.79 & $2.28^{*}$ & $3.64^{* *}$ & $2.83^{* *}$ & 1.64 & $2.74^{* *}$ & $2.38^{*}$ & $2.54^{*}$ & 1.89 & $2.89^{* *}$ & $2.08^{*}$ & $2.08^{*}$ \\
\hline Saghez & -1.85 & -0.35 & 1.30 & 0.28 & -1.19 & 0.54 & 0.73 & $2.23^{*}$ & 1.75 & $2.45^{*}$ & -0.83 & -1.28 \\
\hline Sanandaj & 1.18 & 1.53 & $3.11 \mathrm{v}$ & 1.83 & 0.25 & 1.38 & 0.93 & 1.21 & 1.13 & 1.95 & 1.00 & 0.39 \\
\hline Sarab & -0.20 & 1.87 & 1.64 & 0.48 & 0.03 & 0.57 & 0.34 & 1.83 & 0.37 & $2.20^{*}$ & -0.78 & $-2.63^{*}$ \\
\hline Tabriz & 1.10 & $2.08^{*}$ & $2.65^{* *}$ & 1.92 & $2.03^{*}$ & $2.06^{*}$ & 1.55 & $2.93^{* *}$ & $3.98^{* *}$ & $4.54^{* *}$ & 1.61 & 1.92 \\
\hline Takab & $3.24^{* *}$ & $2.72^{* *}$ & $2.91^{* *}$ & 1.70 & 0.28 & 0.00 & -1.33 & -0.28 & 0.03 & $3.19^{* * *}$ & 1.42 & $2.66^{* *}$ \\
\hline Zanjan & 1.06 & 1.89 & $2.38^{*}$ & $2.49^{*}$ & 0.37 & 1.53 & 0.51 & 2.17 & $2.34^{*}$ & $2.85^{* *}$ & -0.09 & -0.14 \\
\hline
\end{tabular}

(*) trend at $95 \%$ and $(* *)$ trend at $99 \%$ level. 
Table 3. The slope of the monthly reference evapotranspiration ( $\mathrm{mm}$ per day)

\begin{tabular}{|l|c|c|c|c|c|c|c|c|c|c|c|c|}
\hline Station name & Jan & Feb & Mar & Apr & May & Jun & July & Aug & Sep & Oct & Nov & Des \\
\hline Ahar & 0.015 & 0.032 & 0.028 & 0.009 & 0.004 & 0.024 & 0.020 & 0.053 & 0.019 & 0.035 & 0.012 & 0.010 \\
\hline Ardebil & 0.012 & 0.026 & 0.021 & 0.019 & 0.041 & 0.016 & 0.016 & 0.045 & 0.038 & 0.042 & 0.015 & 0.007 \\
\hline Bijar & 0.013 & 0.022 & 0.077 & 0.049 & -0.045 & 0.010 & -0.009 & -0.029 & -0.007 & 0.040 & -0.008 & -0.002 \\
\hline Jolfa & 0.002 & 0.007 & 0.024 & 0.010 & 0.000 & 0.053 & 0.031 & 0.055 & 0.016 & 0.008 & 0.011 & 0.001 \\
\hline Khalkhal & 0.009 & 0.020 & 0.021 & 0.036 & 0.007 & 0.011 & 0.024 & 0.055 & 0.026 & 0.023 & 0.003 & 0.000 \\
\hline Khoramdare & 0.009 & 0.031 & 0.056 & 0.049 & 0.040 & 0.043 & 0.028 & 0.054 & 0.025 & 0.042 & 0.005 & 0.007 \\
\hline Khoy & -0.004 & 0.006 & 0.022 & 0.013 & 0.010 & 0.041 & 0.038 & 0.054 & 0.033 & 0.023 & 0.006 & 0.000 \\
\hline Mahabad & 0.004 & 0.015 & 0.039 & 0.023 & 0.011 & 0.042 & 0.031 & 0.039 & 0.029 & 0.039 & 0.008 & 0.005 \\
\hline Makoo & -0.002 & 0.009 & 0.026 & 0.013 & 0.017 & 0.046 & 0.027 & 0.053 & 0.029 & 0.033 & 0.012 & 0.003 \\
\hline Maragheh & 0.003 & 0.013 & 0.038 & 0.021 & 0.033 & 0.087 & 0.055 & 0.106 & 0.083 & 0.071 & 0.015 & 0.011 \\
\hline Mianeh & 0.000 & 0.012 & 0.026 & 0.004 & 0.002 & 0.041 & -0.001 & 0.038 & 0.034 & 0.025 & 0.003 & -0.001 \\
\hline Oroomieh & -0.001 & 0.005 & 0.020 & 0.014 & 0.013 & 0.043 & 0.030 & 0.044 & 0.035 & 0.019 & 0.000 & -0.004 \\
\hline Parsabad & 0.009 & 0.014 & 0.022 & 0.023 & 0.016 & -0.006 & 0.012 & -0.006 & -0.001 & 0.020 & 0.017 & 0.008 \\
\hline Piranshahr & 0.007 & 0.017 & 0.053 & 0.043 & 0.034 & 0.054 & 0.051 & 0.054 & 0.040 & 0.040 & 0.022 & 0.013 \\
\hline Saghez & 0.012 & -0.004 & 0.023 & 0.003 & -0.033 & 0.012 & 0.026 & 0.052 & 0.032 & 0.034 & -0.006 & -0.008 \\
\hline Sanandaj & 0.003 & 0.003 & 0.035 & 0.022 & 0.010 & 0.037 & 0.030 & 0.035 & 0.014 & 0.019 & 0.004 & 0.003 \\
\hline Sarab & -0.001 & 0.009 & 0.014 & 0.007 & 0.000 & 0.020 & 0.001 & 0.040 & 0.005 & 0.024 & -0.005 & -0.006 \\
\hline Tabriz & 0.008 & 0.028 & 0.049 & 0.035 & 0.039 & 0.071 & 0.040 & 0.076 & 0.085 & 0.069 & 0.018 & 0.014 \\
\hline Takab & 0.007 & 0.015 & 0.031 & 0.017 & 0.010 & 0.004 & -0.030 & -0.010 & 0.001 & 0.030 & 0.003 & 0.006 \\
\hline Zanjan & 0.004 & 0.018 & 0.037 & 0.029 & 0.013 & 0.046 & 0.009 & 0.049 & 0.028 & 0.038 & -0.001 & -0.001 \\
\hline
\end{tabular}
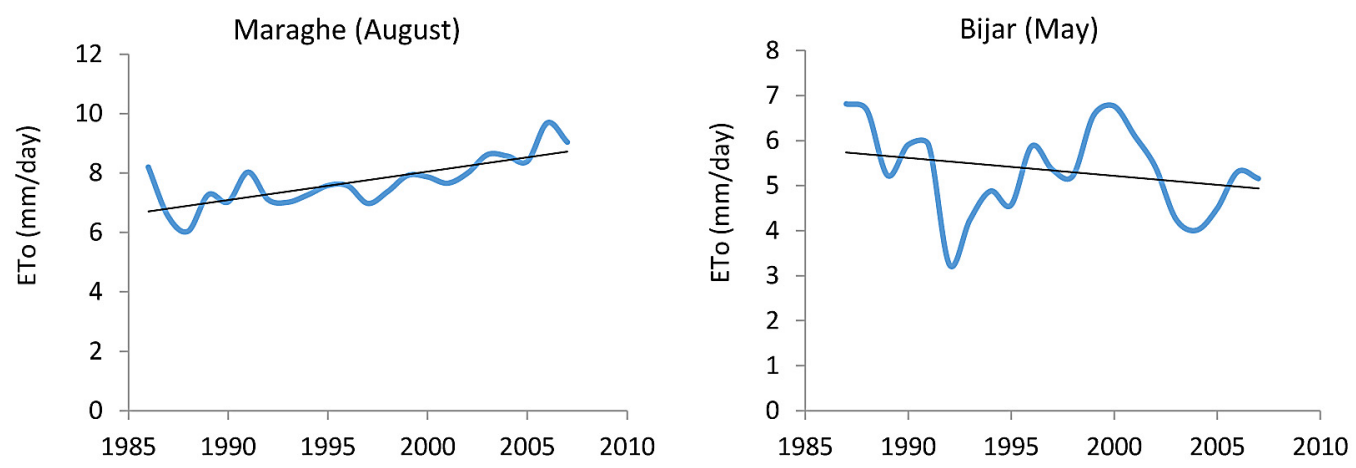

Figure 2. Monthly reference evapotranspiration in stations with the highest slope of trend

In January in all locations, other than central locations of the region and locations surrounding the Takab station, a significant trend is not seen. In February, the eastern border, the central location and a small area in the west of the region, show an increasing trend. In March these locations are expanded and a significant trend is seen in most locations of the region under study. Spatial distribution in April is similar to March; and in the month of May, it is shown only in the Tabriz and the Ardabil stations. In June, this location is expanded in the northwest and a small area in the southeast; and in July this situation continues in the northwest. In August and September, the locations having a significant trend is expanded, and it is seen in all locations other than the southern portion and the northeastern border. In October, locations having a trend is expanded to the northeast. In November and December the expanse of the locations having a trend is decreased, and it is seen only in a narrow border on the north and some areas in the west. However, in December the only location showing a significant decreasing trend is expanded around the Takab station.

Altogether, in analyzing the significance of monthly trends in the northwest of Iran, 42.92 percent of the cases showed an increasing trend, 0.42 percent showed a decreasing trend, and 56.66 percent of the cases showed no trend. 

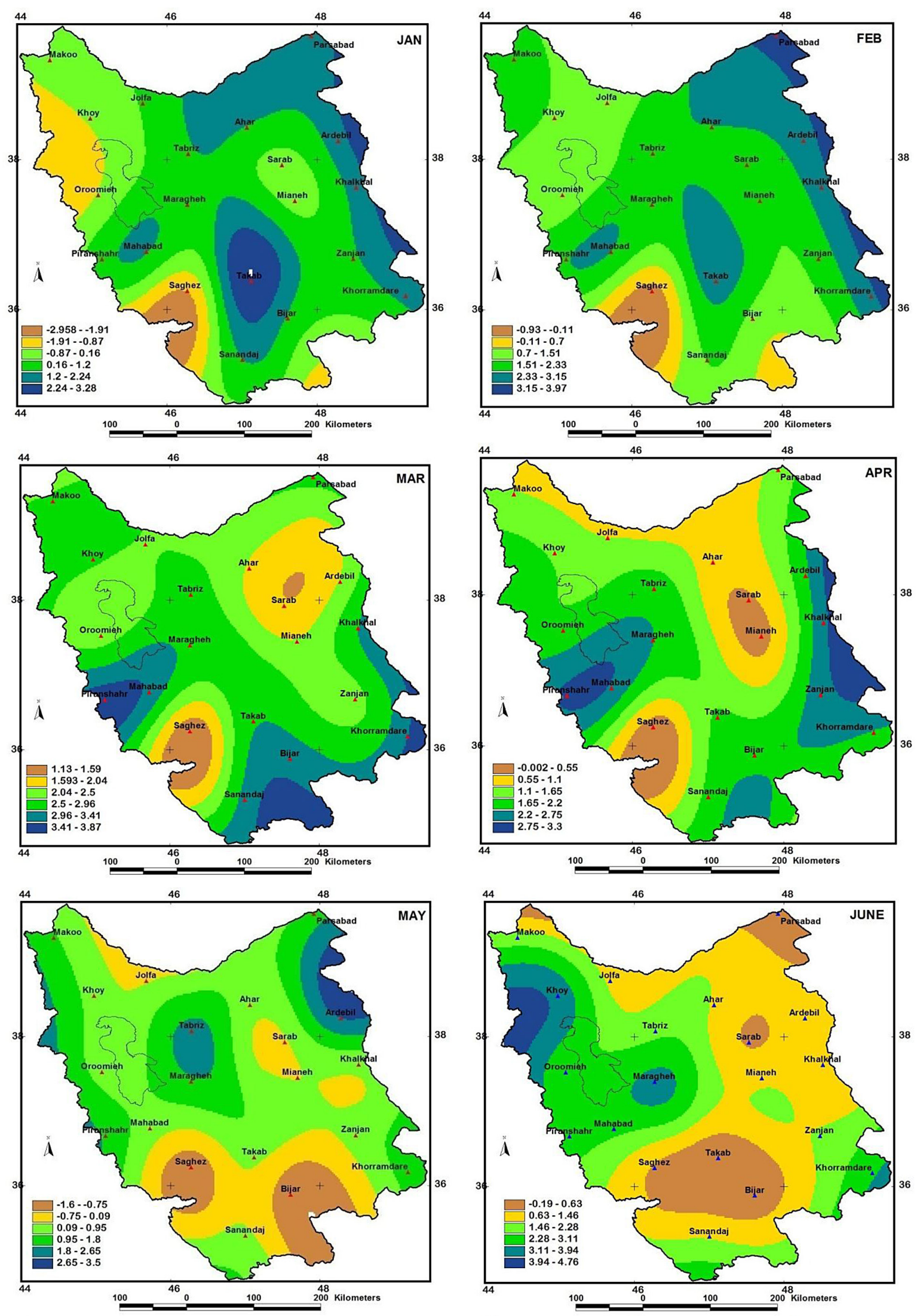

Figure 3. Regional distribution of the evapotranspiration in the northwest on a monthly scale 

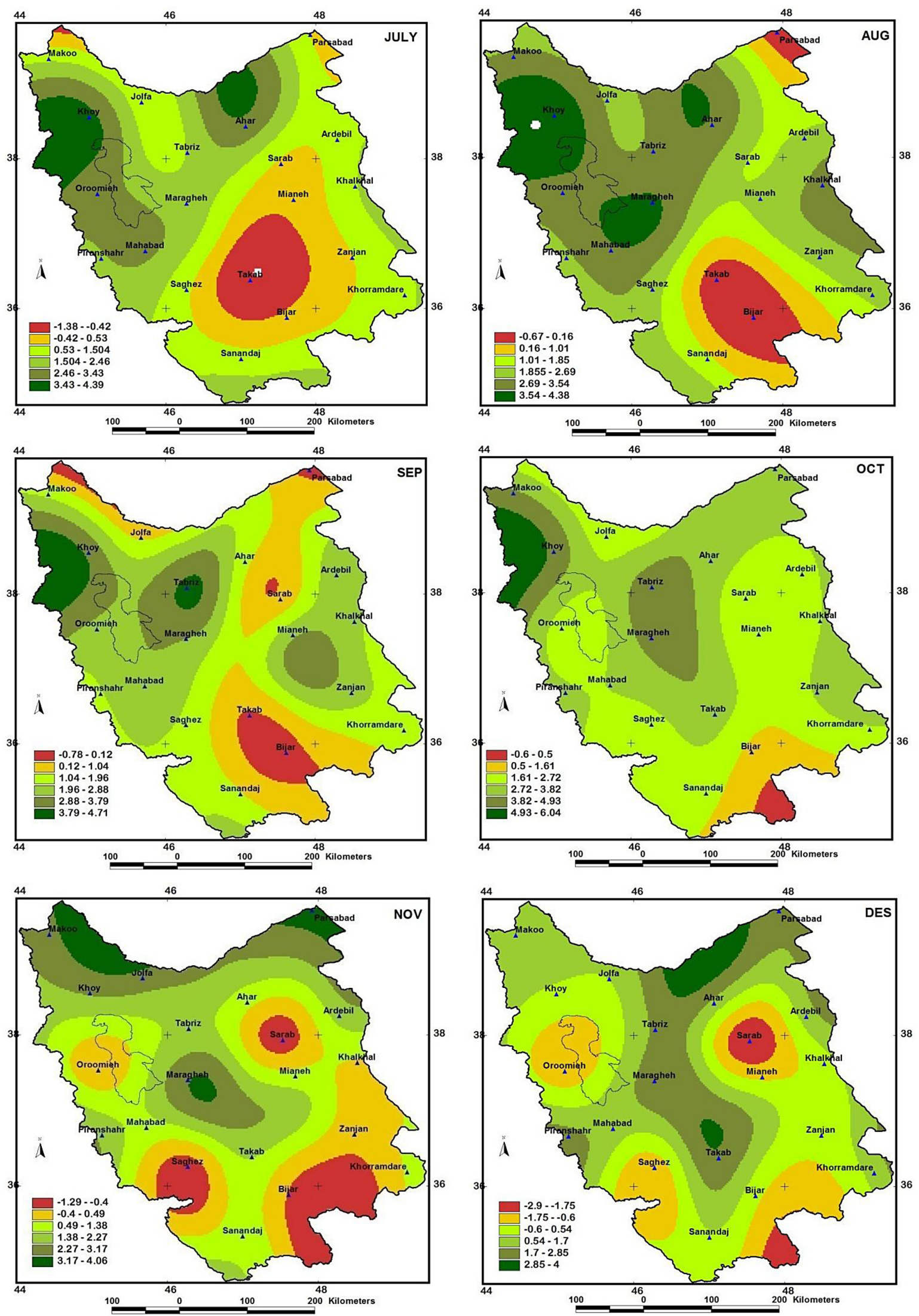

Figure 3. Regional distribution of the evapotranspiration in the northwest on a monthly scale 


\section{Seasonal and annual time series}

The results of the Mann-Kendall test in seasonal and annual periods in all stations under study are shown in Table 4. As we can note from this table, in seasonal and annual time periods, none of the stations show a significant decreasing trend, and all the trends specified are increasing. Among the stations under study, the Sarab and the Saghez stations do not show a significant trend in seasonal and annual analyses. In the spring, only in four stations across the region (Maragheh, Piranshahr, Tabriz, and Ardebil), a significant increasing trend is seen; and in the winter, a significant trend is seen in most stations across the region. In this season, the number of significant trends is more than that in other seasons which shows that winter shows a higher sensitivity to the changes in the trends in ETo in relation to other seasons.

The highest trend was seen in the spring, fall, and also on an annual scale in the Maragheh station which were $2.93,4.43$, and 4.06 millimeters per year; and the fall shows the highest sensitivity. Furthermore, the highest trend in the summer occurred in the Khoy station with an amount of 4.17 millimeters per year, and in the winter it occurred in the Khalkhal station, with an amount of 3.36 millimeters per year.
In table 5, the slope of the annual and seasonal trends in the stations under study is presented. As we can notice from Table 5, among the stations, the Maragheh station in the spring and in the summer and on an annual scale, the Tabriz station in the Fall, and the Bijar station in the Winter have the highest increasing trend of the reference evapotranspiration. The analysis of the results shows that in the Spring 20\%, in the Summer 55\%, in the Fall 70\%, in the Winter $75 \%$, and on an annual scale $60 \%$ of the stations under study showed an increasing trend,

The spatial scattering of the stations having a significant trend, separated annually and seasonally, are shown in Figures 4 and 5. Studying Figure 4, we can observe that in the spring most locations, other that some central, northeastern, and western areas do not show a significant trend. However in the summer, in the entire region, except in the southern areas, and in small borders in the north and the east, a significant trend is observable. Spatial scattering of the stations in the fall and in the winter are similar, other than some small northwestern, southern, and central areas, the rest of the region shows an increasing trend. The spatial scattering of the annual reference evapotranspiration trend in the northwest of the country (Figure 5), shows a significant increasing trend in most stations.

Table 4. Mann-Kendall Statistic (Z) for reference evapotranspiration on a seasonal and annual scale

\begin{tabular}{|l|c|c|c|c|c|}
\hline \multicolumn{1}{|c|}{ Station name } & Spring & Summer & Autumn & Winter & Annual \\
\hline Ahar & 1.27 & $2.82^{* *}$ & $2.28^{*}$ & $2.26^{*}$ & $2.82^{* *}$ \\
\hline Ardebil & $2.12^{*}$ & $2.31^{*}$ & $2.31^{*}$ & $2.71^{* *}$ & $2.88^{* *}$ \\
\hline Bijar & -0.18 & -0.27 & 0.63 & $2.63^{* *}$ & 0.60 \\
\hline Jolfa & 1.33 & 1.92 & $3.11^{* *}$ & 1.95 & 1.52 \\
\hline Khalkhal & 1.10 & $3.02^{* *}$ & $2.06^{*}$ & $3.36^{* *}$ & 1.30 \\
\hline Khoramdare & 1.92 & 1.61 & $2.26^{*}$ & $3.10^{* *}$ & $2.65^{* *}$ \\
\hline Khoy & 1.95 & $4.17^{* *}$ & $4.20^{* *}$ & 1.91 & $3.95^{* *}$ \\
\hline Mahabad & 1.89 & $2.91^{* *}$ & $2.28^{*}$ & $3.16^{* *}$ & $3.10^{* *}$ \\
\hline Makoo & 1.95 & $2.17^{*}$ & $3.33^{* *}$ & $2.21^{*}$ & $2.54^{*}$ \\
\hline Maragheh & $2.93^{* *}$ & $3.58^{* *}$ & $4.43^{* *}$ & $2.26^{*}$ & $4.06^{* *}$ \\
\hline Mianeh & 1.06 & 1.89 & 1.42 & $2.03^{*}$ & 1.84 \\
\hline Oroomieh & 1.75 & $3.05^{* *}$ & 1.13 & 1.66 & $2.71^{* *}$ \\
\hline Parsabad & 0.93 & 0.00 & $3.57^{* *}$ & $2.90^{* *}$ & 1.07 \\
\hline Piranshahr & $2.51^{* *}$ & $2.34^{* *}$ & $2.93^{* *}$ & $2.66^{* *}$ & $2.82^{* *}$ \\
\hline Saghez & -0.34 & 1.80 & 1.66 & 0.06 & 1.30 \\
\hline Sanandaj & 1.35 & 1.30 & $2.23^{*}$ & $2.60^{* *}$ & $2.43^{* *}$ \\
\hline Sarab & 0.28 & 1.02 & 0.87 & 1.55 & 0.68 \\
\hline Tabriz & $2.43^{*}$ & $3.05^{* *}$ & $3.68^{* *}$ & $2.59^{* *}$ & $2.76^{* *}$ \\
\hline Takab & 0.34 & -0.34 & $3.11^{* *}$ & $2.96^{* *}$ & 0.56 \\
\hline Zanjan & 1.47 & $2.09^{*}$ & 1.75 & $2.21^{*}$ & $2.28^{*}$ \\
\hline
\end{tabular}


Table 5. Seasonal and annual slope of the reference evapotranspiration trend in the stations under study

\begin{tabular}{|l|c|c|c|c|c|}
\hline \multicolumn{1}{|c|}{ Station name } & Spring & Summer & Autumn & Winter & Annual \\
\hline Ahar & 0.016 & 0.031 & 0.016 & 0.027 & 0.038 \\
\hline Ardebil & 0.023 & 0.037 & 0.023 & 0.018 & 0.029 \\
\hline Bijar & -0.007 & -0.013 & 0.011 & 0.039 & 0.008 \\
\hline Jolfa & 0.022 & 0.028 & 0.006 & 0.012 & 0.040 \\
\hline Khalkhal & 0.015 & 0.030 & 0.009 & 0.016 & 0.033 \\
\hline Khoramdare & 0.040 & 0.039 & 0.019 & 0.034 & 0.062 \\
\hline Khoy & 0.020 & 0.047 & 0.009 & 0.010 & 0.045 \\
\hline Mahabad & 0.028 & 0.037 & 0.017 & 0.017 & 0.045 \\
\hline Makoo & 0.027 & 0.030 & 0.017 & 0.013 & 0.048 \\
\hline Maragheh & 0.049 & 0.089 & 0.029 & 0.019 & 0.081 \\
\hline Mianeh & 0.019 & 0.025 & 0.009 & 0.014 & 0.028 \\
\hline Oroomieh & 0.020 & 0.038 & 0.005 & 0.008 & 0.016 \\
\hline Parsabad & 0.015 & 0.001 & 0.015 & 0.015 & 0.014 \\
\hline Piranshahr & 0.042 & 0.044 & 0.026 & 0.026 & 0.057 \\
\hline Saghez & -0.003 & 0.039 & 0.008 & 0.000 & 0.031 \\
\hline Sanandaj & 0.014 & 0.021 & 0.011 & 0.017 & 0.029 \\
\hline Sarab & 0.006 & 0.015 & 0.004 & 0.008 & 0.013 \\
\hline Tabriz & 0.047 & 0.060 & 0.033 & 0.027 & 0.076 \\
\hline Takab & 0.011 & -0.005 & 0.014 & 0.018 & 0.009 \\
\hline Zanjan & 0.031 & 0.029 & 0.012 & 0.016 & 0.040 \\
\hline
\end{tabular}
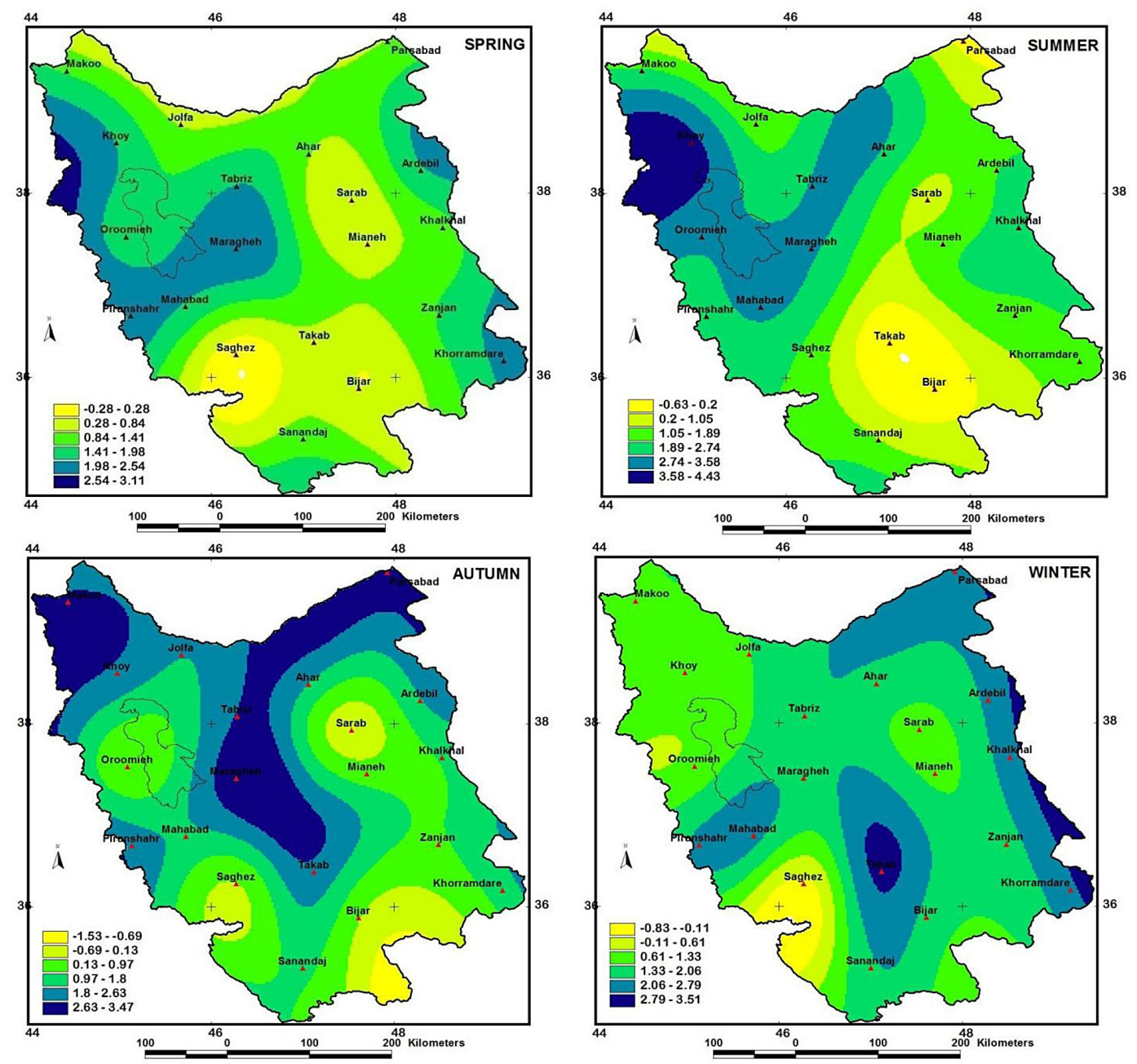

Figure 4. Spatial scattering of the reference evapotranspiration trend on a seasonal scale 


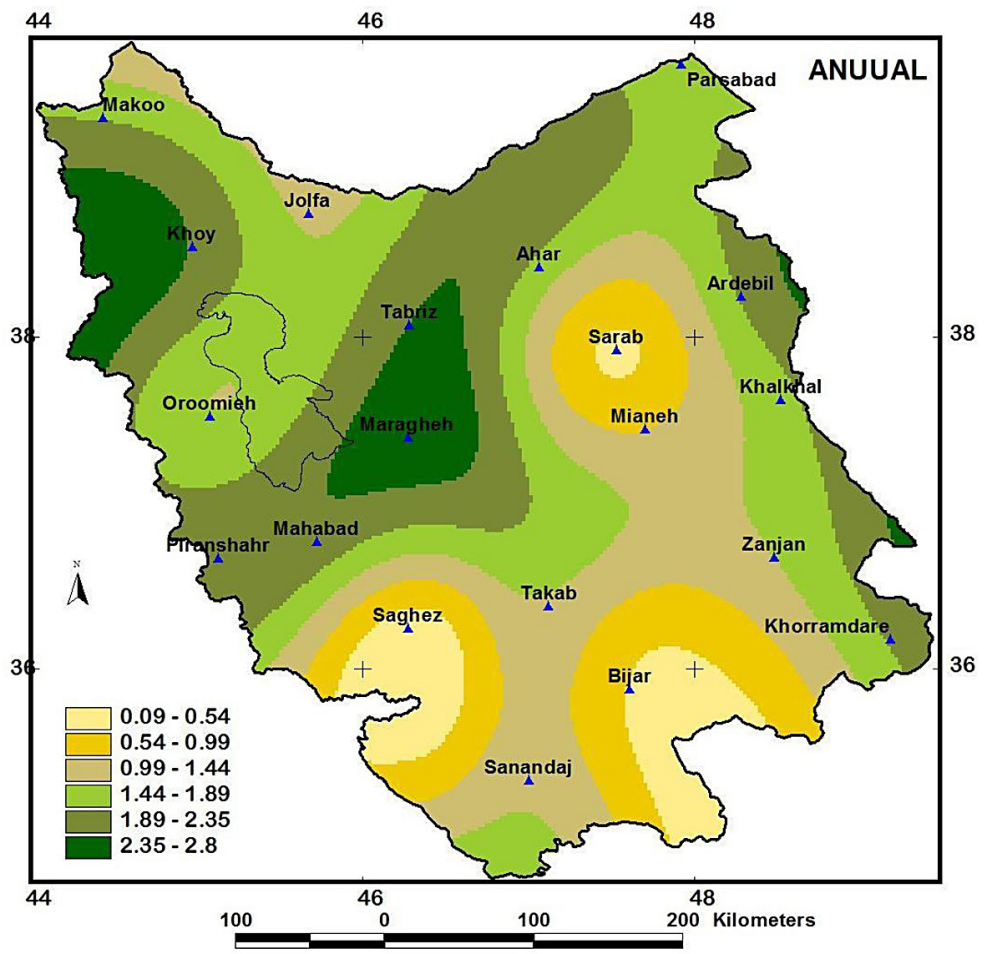

Figure 5. Locational scattering of the reference evapotranspiration trend on an annual scale

\section{CONCLUSION}

Evapotranspiration is one of the important elements of the hydrological cycle and plays an important role in agricultural studies, water resources management planning, irrigation and drainage design. The study of the reference evapotranspiration is essential for offering a proper cropping pattern and optimizing the use of existing water resources. In this study, using the Mann-Kendall test, the trend of reference evapotranspiration for 20 synoptic stations in northwest of Iran during the period from 1986 to 2007 was analyzed. After calculating the amount and direction of trends, the slope of the monthly trends were calculated using the Sen's estimator method. The results showed that the reference evapotranspiration had an increasing trend, and only the Sarab station in the month of December showed a significant decreasing trend. Overall, in the analysis of significance of the monthly trends in northwest Iran, 43.34 percent had a significant trend and 56.66 percent showed no trends.

On an annual and seasonal scale, none of the stations showed a significant decrease, all the specified trends were increasing. In the winter, in most stations in the region showed a significant trend, and the number of stations showing a significant trend in this season was more than other seasons. Analysis of the results shows that in the spring $20 \%$, in the summer $55 \%$, in the fall $70 \%$, in the winter $75 \%$, and on an annual scale $60 \%$ of the stations under study showed an increasing trend. Results obtained by other researchers [Dinpashoh, et al. 2011; Esmailpour and Dinpashoh, 2013] show an increasing trend of evaporation and transpiration.

\section{Acknowledgement}

This Work is supported by the Payame Noor university of I.R of Iran through the research program under Grant.

\section{REFERENCES}

1. Allen R.G., Pereira L.S., Raes D., and Smith M. 1998. Crop evapotranspiration: Guidelines for computing crop water requirements. FAO Irrigation and Drainage Paper, No. 56, FAO, Rome, Italy, $300 \mathrm{p}$.

2. Allen R.G. 2000. Manual REF-ET version Windows 2.0. Available online at www.kimberly.idaho.edu.

3. Bandyopadhyay A., Bhadra A., Raghuwanshi N.S, and Singh R. 2009. Temporal trends in estimates of reference evapotranspiration over India. Journal of Hydrologic Engineering, 14(5), 508-515. 
4. Dinpashoh Y., Jhajharia D., Fakheri-Fard A., Singh V.P., Kahya E. 2011. Trends in reference crop evapotranspiration over Iran. Journal of Hydrology, 399, 422-433.

5. Esmailpour M. and Dinpashoh Y. 2013. Analysis of long-term potential evapotranspiration in the south of the Aras river basin. Geography and Environmental Planning, No. 47, 193-210.

6. Juraj M., Cunderlik Taha B., Ouarada M.J. 2009. Trends in the timing and magnitude of floods in Canada. Journal of Hydrology, No. $375,471-480$.

7. Hajjam S., Khoshkhu Y. and Shamsuddin-Vandi R. 2009. Analysis of changes in seasonal and annual precipitation of selected stations in central Iran using nonparametric methods. Geographical Studies, No. 64, 157-168.

8. Karaca M., Tayanc M., Toros H. 1995. Effects of urbanization on climate of Istanbul and Ankara. Atmospheric Environment, 29, 3411-3421.

9. Kumar S., Merwade V., Kam J. and Thurner K. 2009. Sreamflow trends in Indiana: Effects of long term persistence, precipitation and subsurface drains. Journal of Hydrology, 374, 171-183.

10. Novotny E.V., 2007. Stream flow in Minnesota: Indicator of climate change. Journal of Hydrology, 334, 319-333.

11. Sabzi-Parvar A. and Shadmani M. 2012. Analysis of reference evapotranspiration using Mann-Kendall test and Spearman in arid regions of Iran. Journal of Soil and Water, No. 4, 823-834.

12. Sabzi-Parvar A., Mir-Mousavi Sh. and Nazemosadat M. 2012. The study of long-term variations of reference evapotranspiration in some of the warm climates in the country. Research in Physical Geography, No. 75, 1-17.

13. Serrano A., Mateos V.L., and Garcia J.A. 1999. Trend Analysis of Monthly Precipitation over the Iberian Peninsula for the Period 1921-1995. Phys. Chem. EARTH (B), 24, 85-90.

14. Shirgholami H., Ghahreman B., Alizadeh F. and Bodagh-Jamali J. 2005. Evaluation of reference crop evapotranspiration in Iran. Journal of Agricultural Sciences and Natural Resources of the Caspian, 2 (3), 11-27.

15. Song Z.W., Zhang H.L., Snyder R.L., Anderson F.E., Chen F. 2010. Distribution and trends in reference evapotranspiration in the North China Plain. Journal of Irrigation and Drainage Engin., 136, 240-247.

16. Tabari H., Marofi S., Aeini A., Hosseinzadeh Talaeea P., and Mohammadi K. 2011. Trend analysis of reference evapotranspiration in the western half of Iran. Agricultural and Forest Meteorology, 151 (2), 128-136.

17. Thomas A., 1999. Spatial and temporal characteristics of potential evapotranspiration trends over China. International Journal of Climatology, 20, $16 \mathrm{p}$.

18. Turgay P. and Ercan K. 2005. Trend analysis in Turkish precipitation data. Hydrological processes. Published online in Wiley Inter Science (www.Interscience.wiley.com).

19. Xu Z.X., Takeuchi K. and Ishidiaira H. 2003. Monitoring trend step changes in Japanese precipitation. Journal of Hydrology, 279, 144-150.

20. Zhang Q., Xu CH.Y. and Chen X. 2011. Reference evapotranspiration changes in China: Natural processes or human influences? Theoretical and Applied Climatology, 103, 479-488. 